\title{
EDITORIAL
}

\section{FRAILTY AND SEASONALITY}

\section{E. DENT ${ }^{1,2}$, R.C. AMBAGTSHEER ${ }^{1}$, J. BEILBY ${ }^{1}$, S. STEWART ${ }^{1}$}

1. Torrens University Australia, Adelaide, South Australia, Australia; 2. Baker Heart and Diabetes Institute, Melbourne, Victoria, Australia. Corresponding author: Elsa Dent, Torrens University Australia, Adelaide, South Australia, Australia, elsa.dent@laureate.edu.au

\section{Introduction}

Frailty in older adults is a complex condition in which only a minor external stressor may cause severe complications leading to death $(1,2)$. In the context of the recent devastating bushfires in Australia and the worldwide COVID-19 pandemic, recognising and protecting those affected has magnified the impact and public health importance of frailty. Effects of frailty include bodily deterioration and the failure of physiological systems to cope with changes in the environment (2). Frailty prevalence is around 9-17\% in community-dwelling older adults aged 65 years and over (1) and renders an older adult at heightened risk of adverse outcomes such as infections, hospitalisation, pre-mature admission to care facilities, and mortality $(2,3)$. Although the physiological and functional decline that occurs with frailty usually occurs gradually over a number of years, this functional decline can occur rapidly when external stressors are present (2).

\section{The Role of Seasonality}

While many provocations to the health status of individuals with frailty are random and unpredictable, "seasonality" is not. Over millennia, humans have adapted to survive relatively harsh climates, both by genetic adaptation and through the use of housing, clothing, and heating/cooling technologies (4). This ability to optimise thermoregulatory control has rendered humans as 'seasonality flexible', in that they can survive and adapt to seasonal variations in the environment in nearly every corner of the globe $(4,5)$. However, such protection is not universal and degrades with age, deconditioning and chronic disease (5-7). As recently described $(4,8)$, seasonality in the form of predictable/cyclic changes in climatic conditions (including changing ambient temperatures and humidity levels plus daylight exposure level) is a major driver of morbidity and mortality at the individual level in susceptible individuals; contributing to $10-20 \%$ variations in cardiovascularrelated events throughout the year $(4,8)$. When combined with associated changes in pollution levels and exposure to infectious disease such as seasonal flu, seasonality involves external stressors which can negatively impact older people with frailty.

\section{Seasonal Variations and Frailty}

Older adults with frailty are likely to be characterised as seasonally vulnerable due to their reduced ability to cope with seasonal variations due to lowered physiological functioning. Several physiological systems deteriorate in individuals with frailty. Specifically, cardiovascular and/or pulmonary function can diminish (9-11); the immune system response to external stressors such as the influenza may reduce (12); and the musculoskeletal system can dysfunction - the latter manifesting as sarcopenia (loss of muscle strength, mass, and function) (13). It is also thought that the physiological ability to regulate temperature declines with frailty, given that this is also a common occurrence with the 'ageing process' $(14,15)$. Indeed, the majority of older people require higher temperatures to be within their thermal comfort zone $(14,15)$.

The exact relationship between dysfunctions in physiological processes and seasonal changes with older people with frailty is not yet known - only scant research exists on the topic to date. What we know about susceptibility to seasonal variation comes predominantly from the field of cardiovascular disease (CVD) research. Individuals with CVD are more susceptible than others to seasonal changes, and factors such as sarcopenia, lowered vitamin D levels and cognitive function increase this susceptibility (4).

Psychosocial factors also predispose an older person with frailty to adverse outcomes. Such factors include poverty, social isolation, low home/neighbourhood satisfaction, anxiety and a low sense of control (16). Deprivation in any of these factors will indisputably increase an individual's ability to cope with seasonal stressors.

\section{Seasonal (Winter) Peaks and Frailty}

Undoubtedly, the ability to modulate exposure to seasonal fluctuations will reduce the risk of an individual encountering adverse outcomes (4). Examples of modulating behaviours include adequate dietary intake and physical activity levels, wearing appropriate layers of clothing, as well as using suitable heating and cooling actions. Both the environment and socioeconomic factors also play a large role in coping with seasonal fluctuations, particularly during winter peaks.

Older people with frailty appear to have a reduced ability to modulate their environment. For instance, frailty is often linked with poverty (17), and in turn, a recent Australian study found 


\section{FRAILTY AND SEASONALITY}

that older people with frailty were very likely to be saving heating costs in winter by turning off heating appliances (18). A lack of heating means indoor temperatures are too low, with the authors of this study concluding that this practice may very well be leading to unintended health risks for older people with frailty (18). Similarly a recent cross-sectional study from Japan reported that older adults who were both financially stressed and feeling cold during winter peaks were significantly more likely to be frail (19). One interesting study reported that perceived indoor temperature is perhaps more important than ambient room temperature (18). Notable is that in those older adults with reported colder homes, only those with lower reported socioeconomic status had an increased likelihood of being frail (20). A lack of cultural and behavioural resilience to relatively cold weather, as opposed to that developed in harsher climates elsewhere in the world (21), undoubtedly exacerbates this issue in otherwise milder climates.

Individuals with frailty are also very unlikely to partake in physical activity in colder weather (22). A lack of physical activity reduces muscle strength and physical function (22-24) and it is therefore reasonable to propose that frailty develops and progresses the longer the colder weather goes for (22). Physical performance is also lower in older adults in colder houses during winter (25). Of significance, a recent study of older rural-dwelling older adults in Japan reported that the number of daily steps and the time spent in low-intensity activity (particularly outdoor gardening) dropped off during winter peaks/snowy conditions - however, the time spent in moderate to high intensity physical activity was not influenced by seasonal fluctuations (26) Lower limb resistance-based exercises may be a way to combat this physical activity drop in this population group, based on the promising results of a recent RCT (27).

Other factors that may contribute to an increased susceptibility to seasonal variations in humidity and associated air quality/pollution. Increasingly poor air quality has been recently linked with a low grip strength in older people in six low-middle income countries from the WHO's study of ageing (28). Air quality has been found to be poorer in the summer months in urban areas in the Eastern Mediterranean (29).

\section{Seasonal Flexibility}

Perhaps older people with frailty have lowered individual responses to seasonal fluctuations in temperature. Recently, a model of 'seasonal flexibility' has been developed which identifies physical phenotypes of resilience in patients affected by cardiovascular disease (8) and, more specifically, the syndrome of heart failure (4). This model could potentially be extrapolated out to older people with frailty. Future research would be wise to test this model's applicability to older people with frailty. It may even be that some older adults with frailty have factors which protect them from adverse outcomes. For instance, higher socioeconomic status seems to be one protective factor, based on the above-mentioned studies linking frailty, cold and poverty (19). A good support network and lack of loneliness (thereby avoiding social frailty) may also play a protective role against seasonal fluctuations, although this link is currently subjective with a lack of research into the topic.

\section{Building Resilience}

It is potentially possible for an older person with frailty/ at risk of becoming frail to build resilience to seasonal events. How to build this resilience at both the individual and healthcare system levels is not yet known. The cost effectiveness of such strategies also needs to be investigated. Once known, such information could be used to inform health care policy and resource planning. One such policy in existence is New Zealand's financial support for older adults towards winter heating costs. Whether this policy helps to prevent/ reduce frailty in older adults remains to be investigated. Other potential strategies include public health campaigns targeting older adults ahead of winter flu season - for instance, flu vaccination and proactively identifying individuals with frailty in the primary care setting. In countries such as Australia, there is also the potential for primary care to keep registers of older adults with frailty and/or vulnerability which could be rapidly activated in the case of bushfires and other emergencies. These emergency warning systems could be linked to mobile phones to quickly check if older people are coping ahead of seasonal fluctuations and climatic events.

\section{Additional Research Gaps}

It is reasonable to propose that seasonal fluctuations, including acute climatic events (such as floods and hurricanes) can accelerate frailty development in older adults. Indeed, preliminary research examining the phenomenon of seasonality within the large, longitudinal, population cohort Norwegian Nord-Trøndelag Health (HUNT) study (30), long winters found an increasing the number of cardiovascular and respiratoryrelated, but not cancer-related case fatalities in winter among older individuals with chronic conditions. To what extent, and whether there are mediating (protective) factors to this accelerated frailty development is not yet known. What is also not yet well investigated is the effect of summer peaks (such as heat waves) on older people with frailty and ways to attenuate the effects of this exposure.

The concurrent impact of seasonal variation and frailty needs to be studied globally. This includes collecting much more information on vulnerable populations in Low-Middle Income Countries in whom these intersecting phenomena are likely to be particularly problematic. Whether biomarkers play a role in determining how well an older person with frailty can cope with seasonal fluctuations is also a topic that needs to be investigated.

There is another imperative in closing some of these 


\section{THE JOURNAL OF NUTRITION, HEALTH \& AGING}

important research gaps. From a primary care clinical perspective, we need to understand and formally investigate how to build resilience and plan for the seasonable influences on older adults with frailty. In the day to day clinical interaction we will have to learn to personalise our approach and embrace a more holistic approach including nutrition and exercise in different weather conditions, appropriate heating and clothing. Ultimately, managing frailty is about managing risk, and the risks that seasonality brings can, at least partly, be anticipated.

Acknowledgment: ED is supported by an Australian National Health and Medica Research Council (NHMRC) Early Career Fellowship (\#1112672). SS supported a Senior Principal Research Fellowship by the NHMRC of Australia (\#1135894).

Conflict of interest: The authors declare no COIs.

\section{References}

1. Morley JE, Vellas B, van Kan GA, Anker SD, Bauer JM, Bernabei R, et al. Frailty consensus: a call to action. Journal of the American Medical Directors Association. 2013;14(6):392-7.

2. Dent E, Martin FC, Bergman H, Woo J, Romero-Ortuno R, Walston JD. Management of frailty: opportunities, challenges, and future directions. Lancet (London, England). 2019;394(10206):1376-86.

3. Morley JE. Frailty Fantasia. Journal of the American Medical Directors Association 2017;18(10):813-5

4. Stewart S, Moholdt TT, Burrell LM, Sliwa K, Mocumbi AO, McMurray JJ, et al. Winter Peaks in Heart Failure: An Inevitable or Preventable Consequence of Seasonal Vulnerability? Cardiac failure review. 2019;5(2):83-5.

5. Castellani JW, Young AJ. Human physiological responses to cold exposure: Acute responses and acclimatization to prolonged exposure. Autonomic neuroscience : basic \& clinical. 2016;196:63-74.

6. Degroot DW, Kenney WL. Impaired defense of core temperature in aged humans during mild cold stress. American journal of physiology Regulatory, integrative and comparative physiology. 2007;292(1):R103-8.

7. Székely M, Garai J. Chapter 23 - Thermoregulation and age. In: Romanovsky AA, editor. Handbook of Clinical Neurology. 156: Elsevier; 2018. p. 377-95

8. Stewart S, Keates AK, Redfern A, McMurray JJV. Seasonal variations in cardiovascular disease. Nature reviews Cardiology. 2017;14(11):654-64

9. Kleipool EE, Hoogendijk EO, Trappenburg MC, Handoko ML, Huisman M, Peters MJ, et al. Frailty in Older Adults with Cardiovascular Disease: Cause, Effect or Both? Aging and disease. 2018;9(3):489-97.

10. von Haehling S, Anker SD, Doehner W, Morley JE, Vellas B. Frailty and heart disease. International journal of cardiology. 2013;168(3):1745-7.

11. Charbek E, Espiritu JR, Nayak R, Morley JE. Editorial: Frailty, Comorbidity, and COPD. The journal of nutrition, health \& aging. 2018;22(8):876-9.

12. McElhaney JE, Zhou X, Talbot HK, Soethout E, Bleackley RC, Granville DJ, et al. The unmet need in the elderly: how immunosenescence, CMV infection, co-morbidities and frailty are a challenge for the development of more effective influenza vaccines. Vaccine. 2012;30(12):2060-7.

13. Dent E, Morley JE, Cruz-Jentoft AJ, Arai H, Kritchevsky SB, Guralnik J, et al. International Clinical Practice Guidelines for Sarcopenia (ICFSR): Screening, Diagnosis and Management. The journal of nutrition, health \& aging 2018;22(10):1148-61

14. Hwang RL, Chen CP. Field study on behaviors and adaptation of elderly people and their thermal comfort requirements in residential environments. Indoor air. 2010;20(3):235-45.

15. van Hoof J, Bennetts H, Hansen A, Kazak JK, Soebarto V. The Living Environment and Thermal Behaviours of Older South Australians: A Multi-Focus Group Study. International journal of environmental research and public health. 2019;16(6).

16. Dent E, Kowal P, Hoogendijk EO. Frailty measurement in research and clinical practice: A review. Eur J Intern Med. 2016;31:3-10.

17. Hoogendijk EO, Heymans MW, Deeg DJH, Huisman M. Socioeconomic Inequalities in Frailty among Older Adults: Results from a 10-Year Longitudinal Study in the Netherlands. Gerontology. 2018;64(2):157-64.

18. Willand N, Maller C, Ridley I. "It's not too bad" - The Lived Experience of Energy Saving Practices of Low-Income Older and Frail People. Energy Procedia. 2017;121:166-73.

19. Nakajima Y, M Schmidt S, Malmgren Fänge A, Hoshi T, Ono M, Ikaga T. Cold, poor and frail: A cross-sectional study with community dwelling older people in Japan. Innov Aging. 2018;2(Suppl 1):576-7.

20. Nakajima Y, Schmidt SM, Malmgren Fange A, Ono M, Ikaga T. Relationship between Perceived Indoor Temperature and Self-Reported Risk for Frailty among Community-Dwelling Older People. International journal of environmental research and public health. 2019;16(4).

21. Donaldson GC, Ermakov SP, Komarov YM, McDonald CP, Keatinge WR Cold related mortalities and protection against cold in Yakutsk, eastern Siberia: observation and interview study. BMJ (Clinical research ed). 1998;317(7164):978-82.

22. Hasegawa J, Suzuki H, Yamauchi T. Impact of season on the association between muscle strength/volume and physical activity among community-dwelling elderly people living in snowy-cold regions. Journal of Physiological Anthropology. 2018;37(1):25.

23. Bauer J, Morley JE, Schols A, Ferrucci L, Cruz-Jentoft AJ, Dent E, et al. Sarcopenia: A Time for Action. An SCWD Position Paper. Journal of cachexia, sarcopenia and muscle. 2019;10(5):956-61.

24. Izquierdo M, Morley JE, Lucia A. Exercise in people over 85. BMJ (Clinical research ed). 2020;368:m402.

25. Hayashi Y, Schmidt SM, Malmgren Fänge A, Hoshi T, Ikaga T. Lower Physical Performance in Colder Seasons and Colder Houses: Evidence from a Field Study on Older People Living in the Community. International journal of environmental research and public health. 2017;14(6):651.

26. Nakashima D, Kimura D, Watanabe H, Goto F, Kato M, Fujii K, et al. Influence of seasonal variations on physical activity in older people living in mountainous agricultural areas. J Rural Med. 2019;14(2):165-75.

27. Hasegawa J, Suzuki H, Yamauchi T. Effect of a lower limb strength training programme on physical activity during the snowy season among community-dwelling elderly individuals. Annals of human biology. 2019;46(4):323-9.

28. Lin H, Guo Y, Ruan Z, Kowal P, Di Q, Zheng Y, et al. Association of Indoor and Outdoor Air Pollution With Hand-Grip Strength Among Adults in Six Low- and Middle-Income Countries. The journals of gerontology Series A, Biological sciences and medical sciences. 2020;75(2):340-7.

29. Georgiou GK, Kushta J, Christoudias T, Proestos Y, Lelieveld J. Air quality modelling over the Eastern Mediterranean: Seasonal sensitivity to anthropogenic emissions. Atmospheric Environment. 2020;222:117119.

30. Krokstad S, Langhammer A, Hveem K, Holmen TL, Midthjell K, Stene TR, et al. Cohort Profile: The HUNT Study, Norway. International Journal of Epidemiology. 2012;42(4):968-77. 